\title{
Absorption Measurements for Broad Beams of 1- and 2-Million-Volt X-Rays
}

\author{
By George Singer, Carl B. Braestrup*, and Harold O. Wyckoff
}

\begin{abstract}
Experimentally determined concrete-absorption curves are given for wide-angle X-ray beams produced by a 1- and 2-million-volt resonance generator. Data on the variation of X-ray intensity with the distance from a concrete barrier are included. With this information as a basis, the thickness of a concrete barrier necessary for protection against a broad X-ray beam has been computed for 1- and 2-million-volt X-rays and for various tube currents and barrier-to-target distances.
\end{abstract}

\section{Introduction}

One- and two-million-volt X-radiation is now used routinely for industrial radiography. In this application the cone of radiation used is much broader than is common in other applications. This is so for two reasons. The first is that the use of a large field effects a saving in the time required to radiograph a large object or a number of small objects in one lot. The second is that the massive cones needed to restrict the field of very penetrating radiation must necessarily limit the mobility of the X-ray generator; their use is therefore commonly avoided, although desirable for other reasons.

Concrete, being structurally self-supporting, relatively inexpensive, and easily fabricated, has become the standard material for the construction of barriers for protection against very penetrating radiation. Theoretical absorption curves applicable to such barriers are not currently available for wide-angle beams. In the calculations for such absorption curves a correction must be made for scattering which retains the scattered photons within the confines of the primary beam, a process tending to reduce the attenuation for wide-angle beams in comparison with that for narrow beams of the same radiation.

*Senior Physicist, Department of Hospitals, City of New York.
This problem has been recognized in several papers relating to X-ray protection. ${ }^{2}{ }^{2} 34$ However, there are considerable technical difficulties involved in obtaining such data experimentally. For this reason all discussion in the literature relating to the increase in barrier thickness needed for wide-angle beams over that for narrow beams is of a general and indirect nature, and is not sufficiently detailed for specific application in the development of protection specifications.

In the design of protective barriers, information is also needed on the variation of X-ray-dosage rate with distance from the protective barrier to the position at which personnel will be stationed. Because of scattering from the barrier it is to be expected that for very penetrating radia-

1 R. Jaeger and A. Trost, Elektrotech. Z. 61, 1,025 (1940).

2 T. R. Folson and E. F. Focht, Am. J. Roentgenol. Radium Therapy 51, 76 (1944).

3 G. Singer and George C. Laurence, Ind. Radiology 40, Fall (1945); Radiology 46, 69 (1946).

4. Failla, Am. J. Roentgenol. 54, 553 (1945).

\section{Contents}

I. Introduction

II. Method_...

III. Results _............. 149

IV. Conclusions . . . 150 
tion this variation will not follow the inversesquare law for the distance measured from the tube target. It is to be expected that this variation will be more rapid than indicated by this law because both the X-ray-tube target and the irradiated volume of concrete act as sources of radiation.

It is the purpose of this paper to present (1) experimental data on absorption of X-rays in concrete for wide-angle beams generated by voltages of 1 and 2 million volts, (2) preliminary data on the variation of the dosage rate with the distance from a protective barrier, and (3) data on concrete protection requirements for 1 - and 2-million-volt radiation under certain conditions which obtain in industry.

\section{Method}

The experimental arrangement used in obtaining the basic data given below is indicated in figure 1 . The concrete wall, $C$, is the main wall of the building housing the generator and is 41 inches thick; $D$, is the covered maze within which the ionization measurements were made.

Dosage measurements were made by calibrated dosage instruments designed by Braestrup. ${ }^{\circ}$ Three sizes of ionization chambers were used; their characteristics are listed in table 1 . The ionization chamber potentials were measured before and after irradiation by means of a string electrometer which is an integral part of the dosage meter. All ionization chambers were calibrated

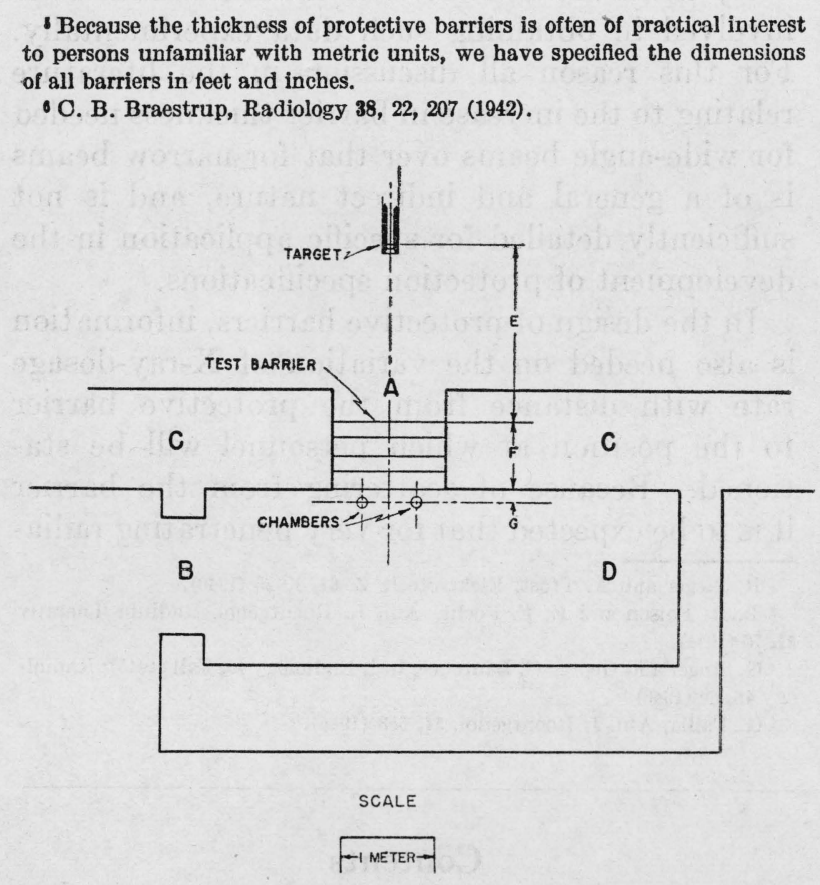

FIgURE 1.-Experimental arrangement showing two sets of concrete test blocks in place.

A total of three sets were used. with both $175-\mathrm{kv} \mathrm{X}$-rays and gamma-rays from radium. Both calibrations agreed very well with the theoretical values based upon the air volume and capacitance. At the National $\mathrm{Bu}-$ reau of Standards the small thimble chamber and the electrometer head were checked against a similar instrument combination with 1-millionvolt radiation and were found to be in agreement therewith to within 2 percent.

TABLE 1.-Ionization chambers

\begin{tabular}{|c|c|c|c|c|c|}
\hline \multirow{2}{*}{ Type } & \multirow{2}{*}{$\begin{array}{c}\text { Wall mate- } \\
\text { rial }\end{array}$} & \multicolumn{2}{|c|}{ Inside dimensions } & \multirow{2}{*}{ Volume } & \multirow{2}{*}{$r /$ Div. $^{1}$} \\
\hline & & Diameter & Length & & \\
\hline & & $\mathrm{cm}$ & $\mathrm{cm}$ & $\mathrm{cm}^{\mathrm{s}}$ & \\
\hline $\begin{array}{l}\text { CX-1, Cylindri- } \\
\text { cal. }\end{array}$ & Bakelite.... & 12.05 & 21.85 & 2490 & $0.23 \times 10^{-8}$ \\
\hline SX-11, Spherical & Polystyrene. & 10.5 & & 624 & $.79 \times 10^{-8}$ \\
\hline D-1, Thimble....... & Catalin..... & 0.7 & 2.15 & 0.783 & 1.0 \\
\hline
\end{tabular}

1 Dose in roentgens per scale division of electrometer.

The barrier material consisted of concrete blocks of density $130 \mathrm{lb} / \mathrm{ft}^{3}$, measuring $5 \frac{3 / 4}{4}$ by $73 / 4$ by $23^{3 / 4}$ in. These were laid in the doorway, $A$, shown in figure 1. Measurements were made through sets of double layers of these blocks; one $5 \% 4$ in. and the other $7 \frac{3}{4}$ in. thick. The layers were staggered so that the planes of the cracks between blocks did not pass through either the tube target or ionization chamber. The opening remaining between the top of the test barrier and the lintel of the doorway to the maze was filled with lead brick. For this arrangement both the radiation leakage through the doorway, $B$-produced by the rays scattered through a glass-brick window above the main wall, $C$-and that through cracks in the test barrier were found to be negligible in comparison with the dosage rate at the position of the test ionization chambers. 
The distance, $E$, in figure 1 was $1.83 \mathrm{~m}$ in all cases; $F$ is the barrier thickness. This thickness was converted to thickness of concrete of a density of $147 \mathrm{lb} / \mathrm{ft}^{3}$ before plotting. The wall-to-center-ofchamber distance, $G$, varied from 2 to 4 in. for all plotted points. The ionization chambers were placed as near as practicable to the radiation barrier. It will be shown later that this position gives the minimum apparent absorption.

The X-ray generator used is the 2-million-volt $\mathrm{X}$-ray resonance generator described by Charlton and Westendorp, ${ }^{7}$ which is operative at both 1 and 2 million volts. All measurements were made with X-radiation transmitted through the tube target along the axis of the tube. The anode cone consisted of a cylinder with a lead wall $5 \mathrm{~cm}$ thick, the end of which was shaped so as to confine the X-ray beam to a cone of radiation measuring approximately $70^{\circ}$ at its apex.

1 E. E. Charlton and W. F. Westendorp, Electronics 17, 128 (1944). We are indebted to the General Electric Co. and to E. E. Charlton, of their Research Laboratory, for facilities that were made available to us in carrying out these experiments.

\section{Results}

The attenuation curves obtained are shown in figure 2. As a check on the reliability of the method used, transmission measurements for 2 -million-volt radiation through a solid concrete wall $42 \mathrm{in}$. thick of density $152 \mathrm{lb} / \mathrm{ft}^{3}$ were also

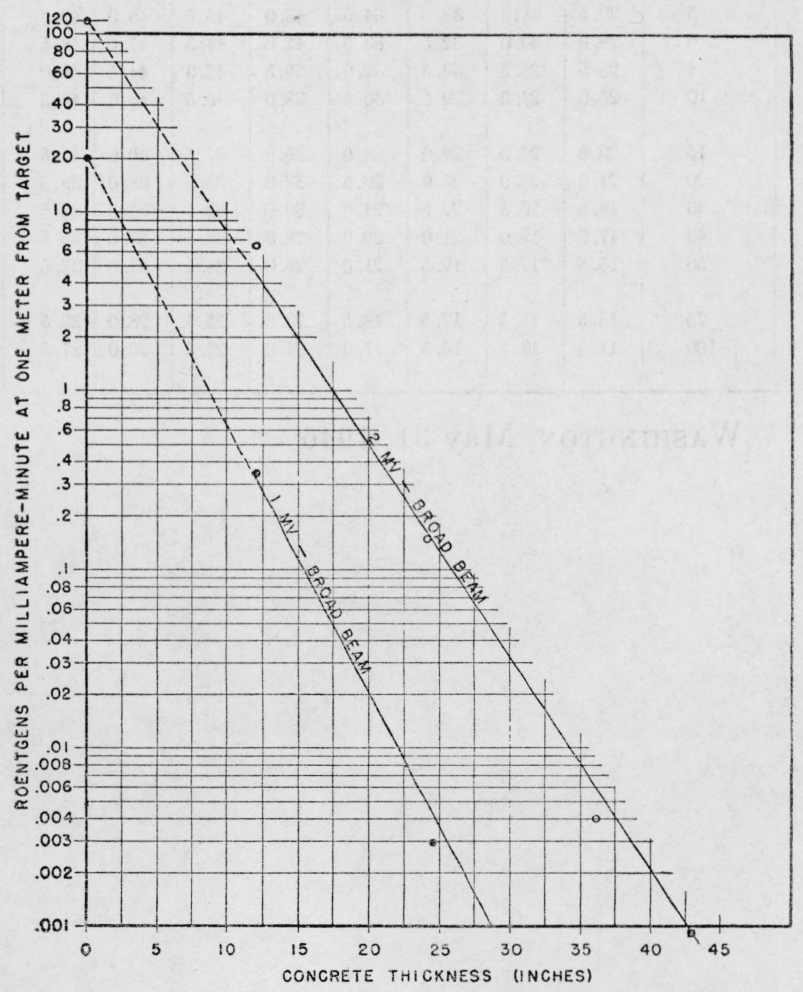

Figure 2.-Concrete absorption curves for $70^{\circ}$ beams of 1 and 2-million-volt $X$-rays.

All measurements were made with the radiation transmitted through a tungsten target along the tube axis. A resonance generator was used. The voltage waveform of such generators is sinusoidal. All indicated voltages are peak or crest values. made. The single point so obtained is plotted in figure 2 at a thickness of about 43 in.

The effect of chamber-to-wall distance on the apparent attenuation is illustrated by the curves in figure 3. The ordinate is in arbitrary units. It is obtained by dividing the dose per milliampere minute by the square of the sum of the distances $E, F$, and $G$. The abscissa is the chamber-wall distance, $G$, shown in figure 1 . If there were neither scattering in the wall nor absorption in the air, each set of plotted points should give a straight line with zero slope. Actually, because of wall scattering, the value of the ordinate decreases with increase of abscissa. These plotted points

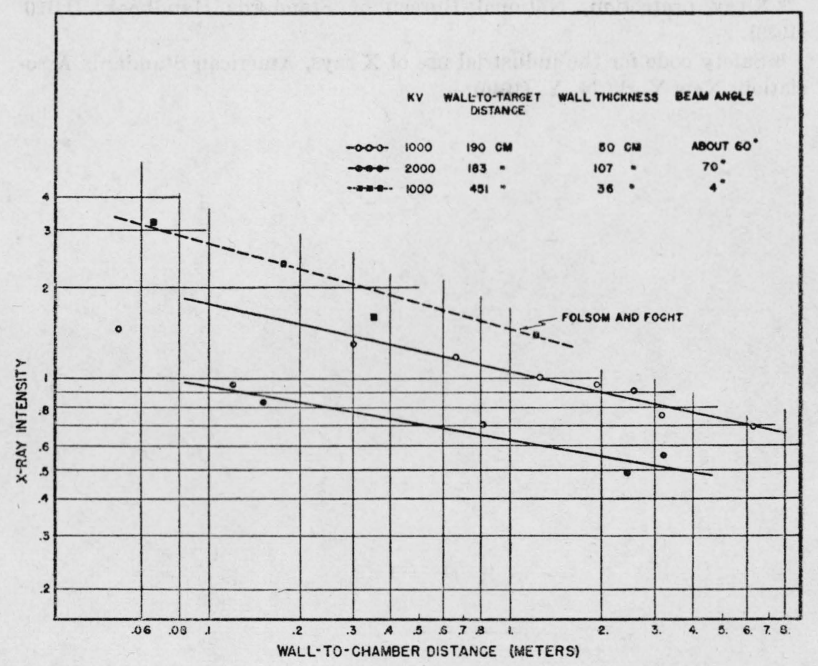

Frgure 3.-Variation of $X$-ray dose with distance from a concrete protective barrier.

The abscissa is the distance to the ionization chamber measured from the side of the barrier from which the radiation emerges. The ordinate is obtained by dividing the dose per milliampere minute by the square of the distance from the $\mathbf{X}$-ray source to ionization chamber. 
fall along a straight line for each experimental setup. The slopes measured on a linear scalenot the logarithmic scale of figure 3 -are approximately 0.25 . This is so not only for our own 1-million-volt and 2-million-volt data for $70^{\circ}$ beams but also for the 1 data on a $4^{\circ}$ beam pub- lished by Folson and Focht. ${ }^{8}$ Accordingly, it may be concluded that within these limits the beam angle has no important effect on the change in apparent attenuation with chamber-to-wall distance.

8 Folson and Focht, Am. J. Roentgenol. Radium Therapy 51, 76 (1944).

\section{Conclusions}

From the data presented above it is possible to compute for broad X-ray beams the thickness of concrete barriers necessary for protection against 1- and 2-million-volt X-radiation from targets of the transmission type. Such targets are standard in this quality range. In table 2 the thickness of such barriers is listed for 1- and 2-million-volt $\mathrm{X}$-radiation and for the various tube currents and target distances normally encountered in practice. The tubular values given therein were computed directly from the absorption curves of figure 2 . A few points at short distances and high currents required linear extrapolation for their determination. Absorption of X-radiation by air has been neglected. A permissible daily dose of $0.1 \mathrm{r}$ has been assumed. ${ }^{9,10}$ It was further assumed that the dosage rate per milliampere at $1 \mathrm{~m}$ for a 1-million-volt X-ray generator is $20 \mathrm{r} / \mathrm{min}$ and for a 2-

\footnotetext{
- X-ray protection, National Bureau of Standards Handbook HB20 (1936).

${ }^{10}$ Safety code for the industrial use of X-rays, American Standards Association, New York, N. Y. (1946).
}

million-volt X-ray generator, $120 \mathrm{r} / \mathrm{min}$ and that the person to be protected will normally be stationed near the protective barrier.

TABLE 2.-Thickness of concrete of density $147 \mathrm{lb} / \mathrm{ft}^{3}$ required for protection against broad beams of $X$-rays for the current, distance, and voltage indicated

\begin{tabular}{|c|c|c|c|c|c|c|c|c|}
\hline \hline \multirow{2}{*}{$\begin{array}{c}\text { Target } \\
\text { distance }\end{array}$} & \multicolumn{3}{|c|}{ 1-million-volt X-rays } & \multicolumn{3}{|c|}{ 2-million-volt X-rays } \\
\cline { 2 - 8 } & $0.5 \mathrm{ma}$ & $1.0 \mathrm{ma}$ & $2.0 \mathrm{ma}$ & $3.0 \mathrm{ma}$ & $0.5 \mathrm{ma}$ & $1.0 \mathrm{ma}$ & $2.0 \mathrm{ma}$ & $3.0 \mathrm{ma}$ \\
\hline Feet & In. & In. & In. & In. & In. & In. & In. & In. \\
4 & 30.5 & 32.5 & 34.5 & 36.0 & 44.5 & 47.0 & 49.5 & 51.0 \\
5 & 29.5 & 31.5 & 33.5 & 34.5 & 43.0 & 45.5 & 48.0 & 49.5 \\
6 & 28.0 & 30.0 & 32.5 & 33.5 & 42.0 & 44.5 & 47.0 & 48.5 \\
8 & 26.5 & 28.5 & 30.5 & 32.0 & 39.5 & 42.0 & 44.5 & 46.0 \\
10 & 25.0 & 27.0 & 29.5 & 30.5 & 38.0 & 40.5 & 43.0 & 44.5 \\
& & & & & & & & \\
20 & 23.0 & 25.0 & 27.0 & 28.0 & 35.0 & 37.5 & 40.0 & 41.5 \\
30 & 21.0 & 23.0 & 25.0 & 26.5 & 33.0 & 35.5 & 38.0 & 39.5 \\
40 & 18.5 & 20.5 & 22.5 & 24.0 & 30.0 & 32.5 & 35.0 & 36.5 \\
50 & 17.0 & 19.0 & 21.0 & 22.0 & 28.0 & 30.5 & 33.0 & 34.5 \\
75 & 15.5 & 17.5 & 19.5 & 21.0 & 26.0 & 28.5 & 31.0 & 32.5 \\
100 & 13.5 & 15.5 & 17.5 & 18.5 & 23.0 & 25.5 & 28.0 & 29.5 \\
& 11.5 & 13.5 & 15.5 & 17.0 & 21.0 & 23.5 & 26.0 & 27.5 \\
\hline
\end{tabular}

Washington, May 31, 1946 